\title{
Design of an Axial Flux Inductor Type Synchronous Motor With the Liquid Nitrogen Cooled Field and Armature HTS Windings
}

\author{
Hidehiko Sugimoto, Teppei Tsuda, Takaya Morishita, Yoshinori Hondou, Toshio Takeda, Hiroyuki Togawa, \\ Tomoya Oota, Kazuya Ohmatsu, and Shigeru Yoshida
}

\begin{abstract}
A liquid nitrogen cooled axial flux type high temperature superconducting (HTS) synchronous motor was designed. This motor is an eight-pole inductor type synchronous motor with six armature windings. The field windings and armature windings are made of the BSCCO HTS wires. We called it Inductor type Flux Control Superconducting (IFCS) motor, and its output is $400 \mathrm{~kW}$ at the rated speed of $250 \mathrm{rpm}$. Until now, there were few armature windings using HTS wires, because of AC losses generation when the wires are used in the alternating magnetic field. In this motor, we used iron cores to decrease AC loss. Also because of the help of iron cores, it is possible to make use of armature winding at liquid nitrogen temperature. Furthermore, inductors were employed in the rotor. As a result, the cryostats that contain field HTS windings and armature HTS windings can be fixed; also we do not need the excitation devices such as the brushes and slip ring and the cooling devices such as the rotary joint to offer the path for coolant to flow.
\end{abstract}

Index Terms-Axial flux type, BSCCO-HTS wire, inductor type flux control superconducting (IFCS) motor, liquid nitrogen coolant, stator cooling system.

\section{INTRODUCTION}

W ITH the goals of developing high efficiency, small size and simple system, a fully HTS synchronous motor operated at liquid nitrogen temperature level was considered and designed. There were several reports on fully superconducting rotating machines which applied $\mathrm{NbTi}$ wires to the field and armature windings [1], [2]. However, all these rotating machines including other reported rotating machines used low temperature superconducting (LTS) wires, which operated at the temperature of liquid helium. The commercialization of LTS-technology is strongly influenced by the cost and the complexity of the liquid helium cooling system. The recent reported HTS rotating machines which focused on mass-produced BSCCO wires, did not employ the liquid helium cooling

Manuscript received October 28, 2006.

H. Sugimoto, T. Tsuda, T. Morishita, and Y. Hondou are with the Department of Electrical and Electronic Engineering, University of Fukui, 901-8507, Japan (e-mail: sugimoto@fuee.fukui-u.ac.jp).

T. Takeda, H. Togawa and T. Oota are with Superconductive Ship Propulsion System Dev., Ishikawajima-Harima Heavy Industries Co. Ltd., 100-8182, Japan (e-mail: toshio_takeda@ihi.co.jp).

K. Ohmatsu is with HTS R\&D Department, Electric Power and Energy Research Laboratories, Sumitomo Electrical Industries Ltd., Osaka 554-0024, Japan (e-mail: ohmatsu@ sei.co.jp).

S. Yoshida is with the Department of Engineering, Cryogenic Project, Development and Engineering, Taiyo Nippon Sanso Corp., Ibaraki 300-2611, Japan (e-mail: Sgr.Yoshida@tn-sanso.co.jp).

Digital Object Identifier 10.1109/TASC.2007.898110 system [3]-[7]. Some of these are discussed briefly in the following paragraphs.

The motor reported in [3] is a revolving-field type synchronous motor. The field windings are made of BSCCO HTS wires and the armature windings are made of copper wires. That is why the motor in [3] uses G-M coolers to cool the $\mathrm{BSCCO}$ wires down to $32 \mathrm{~K}$ to obtain high field current density, which can lead to the high magnetic flux density in the air-gap. The iron core is used in neither the field nor the armature because of its saturation. In this case, the stainless steel reinforced compensation is necessary for the wires, and the support structure for HTS windings is necessary too.

The synchronous generator in [4] applies the BSCCO wires to the field windings and employs a conventional copper armature. The different things are that it employs the liquid nitrogen coolant and the iron core. The iron core which leads to less flux penetrating the HTS windings can make sure the BSCCO wires operate well at liquid nitrogen temperature. On the other hand, the iron core of this generator also causes some faults. In this generator, the iron core is also cooled, so it is easy to cause extra eddy current loss because of the effect of the flux produced by the armature winding. Also, there is extra cooling loss due to the extra eddy current loss. Furthermore, it is hard to make the machine smaller when using iron cores in the field windings, since the saturation of iron cores leads to limitation on the flux density.

As the machines reported in [3] and [4], most of the developed HTS rotating machines are radial flux revolving-field type synchronous machines with rotor cooling systems. These machines apply HTS wires to field windings and apply copper wires to the armature windings [5]. Because of the rotor cooling system, extra supporting parts are needed, also the construction of the cryostat become complex. Thus, it is difficult to make the motor smaller.

In our research, we provide a novel method to make a variable-field type motor smaller, more efficiency, also the cooling system simpler. The methods are shown as follows,

1) The BSCCO-2223 wires are used both for field windings and armature windings.

2) Applying inductors to the rotors to fix the cooling system.

3) This motor adopts axial flux configuration.

4) The cores are arranged at the center of the armature windings.

By applying the methods mentioned above, BSCCO wires can be used at the liquid nitrogen temperature; also the am- 


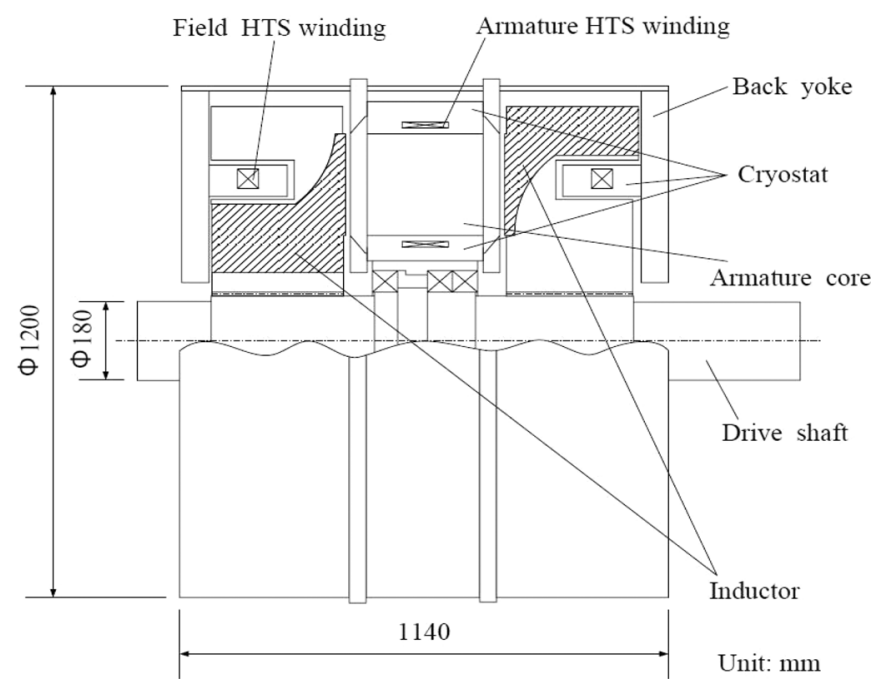

Fig. 1. Overview of the IFCS motor.

pere-conductors were increased. It is anticipated that a high efficiency and small size fully HTS motor should be achieved. In addition, it is easy to do motor's maintenance because of the simpler cooling system and simpler excitation system. We gave the motor the name of Inductor type Flux Control Superconducting (IFCS) motor. This paper presents the details of the design and the analysis of the IFCS motor.

\section{DESIGN}

\section{A. Overview}

The axial flux synchronous IFCS motor that we designed uses the BSCCO wires both for field windings and armature windings. The rated output is $400 \mathrm{~kW}$ at $250 \mathrm{rpm}$. The outside diameter of this motor is $1200 \mathrm{~mm}$ and the length is $1140 \mathrm{~mm}$.

A schematic drawing of this motor is depicted in Fig. 1. This motor employs one armature and two field windings. The armature is fixed between two field windings. The rotor employs inductors, so the field windings and armature windings do not rotate. Meanwhile, all the windings are fixed, excitation devises such as slip rings and brushes are not necessary.

\section{B. The Decisive Factors of a Motor Size}

A motor torque is calculated by multiplying the magnetic loading and the electric loading. It means, the size of one motor is decided by two factors, the peak mid-gap flux density and the ampere-conductors of the armature. Larger flux density or higher ampere-conductors both can make a motor smaller. Here, we used the way of increasing the ampere-conductors by applying HTS wires to the armature windings.

\section{The Characteristics of the BSCCO Wires}

Figs. 2(a) and (b) show the relations of the magnetic flux density and the critical current of the BSCCO wires that are used in field windings and armature windings at different temperatures. The measured values were provided by the producer of the BSCCO wires. Fig. 2(a) shows the critical currents at different temperatures when the flux penetrates wires at horizontal direction, while Fig. 2(b) shows flux penetrates wires at vertical

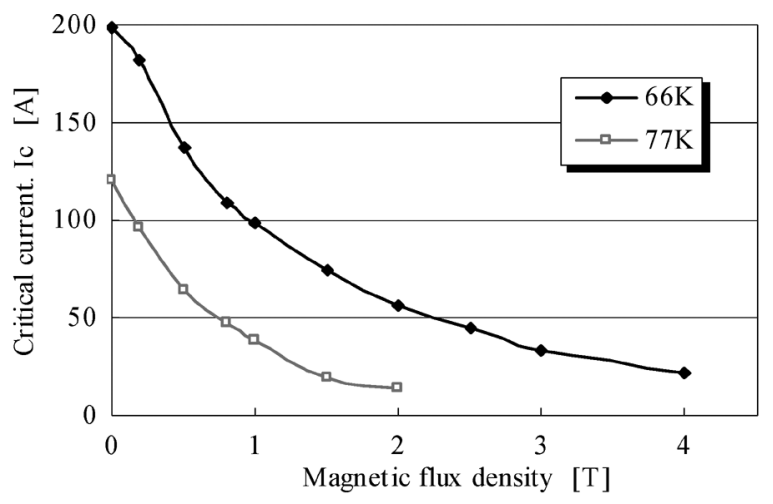

(a)

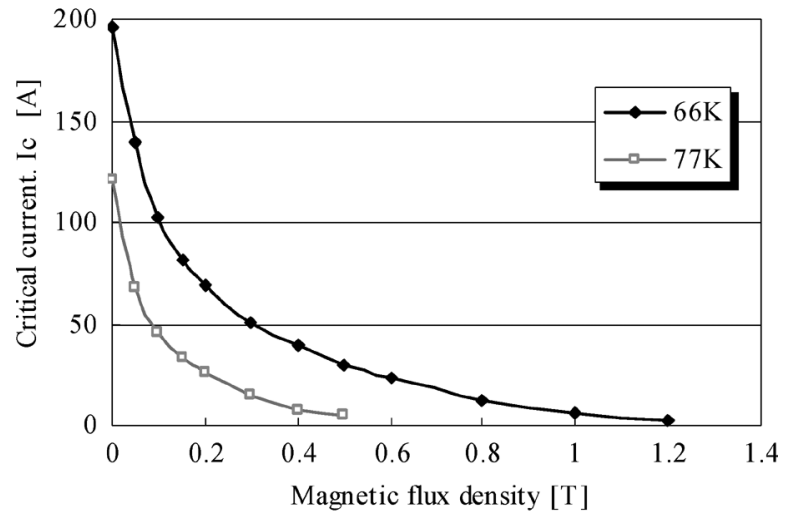

(b)

Fig. 2. Relation of critical current and magnetic flux density of the BSCCO2223 wire at $66 \mathrm{~K}$ and $77 \mathrm{~K}$. (a) Horizontal direction. (b) Vertical direction.

direction. From these figures, it is clear that high current density can be obtained under low flux density even though the wires are arranged at relatively high temperatures ( $64 \mathrm{~K}$ to $77 \mathrm{~K}$ ).

\section{The Structure of the Armature}

The armature has six HTS concentrated windings and six armature cores. The core is arranged at the center of the HTS winding. Three pairs of concentrated windings are connected as star-connected circuit to supply 3-phase power. The armature windings are put into the cryostat. The cryostat, which is made of Fiber Reinforced Plastics (FRP), contains two layers: the inner layer is filled with liquid nitrogen while the outer layer is used for vacuum insulation. FRP is a very popular material for the cryostat because it is light, strong and eddy current free.

To prevent the eddy current, a room temperature laminated core is employed for the iron core and fixed on the outside of the cryostat. Moreover, armature iron core is used not only for reducing the flux penetrating the armature windings, but also provides protection on HTS wires because the majority of the load torque acts on armature iron cores. Also there is less leakage flux due to the reduced reluctances of the motor.

\section{E. The Structure of the Field}

The excitation field is created by a HTS winding, a back yoke, and eight inductors. The field HTS winding is put into the cryostat then to be fixed at the back yoke. This cryostat is also made from FRP and has the same layer structures as the armature cryostat. 


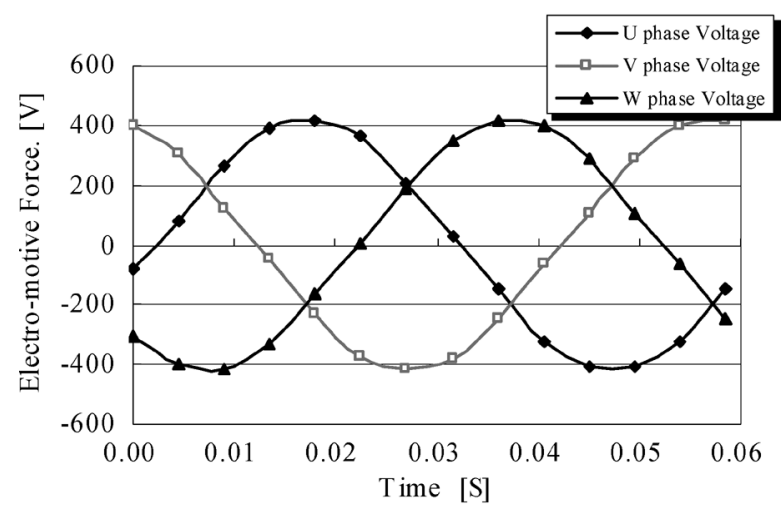

Fig. 3. Induced Electro-motive Force wave form.

The inductors are made from high permeability material. The most possible main flux can be collected to the armature core due to the special shape of the inductors. There are eight inductors in each side of the field. These inductors are equipped with the shaft to run. Here, the inductors are used not only to collect the main flux, but also to prevent the alternating magnetic field acting directly on the field windings.

\section{F. Cooling System}

All the components of the cryostat can be fixed because of the inductors configuration. As a result, rotary joint and hollow shaft which are used to offer the path for the coolant flowing between the rotating part and the stationary part are not necessary, the torque tube for transferring torque between the warm side and the cold side is not necessary too.

Attribute to the axial flux type, the cryostat which can carry the iron core on the outside becomes less complex. This directly leads to a simpler cooling system. As a result, the obstacle caused by complex cooling system in the path of making a small size motor can be swept away.

The sub-cooled liquid nitrogen at $66 \mathrm{~K}$ is supplied to each cryostat by the circulation pump.

\section{ANALYSIS}

The analysis was done by FEM (Finite Element Method). The values of the exciting current and the armature current were chosen among an available range according to the Fig. 2(a) and (b) when the wires were operated at $66 \mathrm{~K}$. Based on these values, we obtain the rated exciting current of $25 \mathrm{~A}$, and the rated peak armature current of 30 A per HTS wire. Fig. 3 shows the induced electro-motive force's phase voltage when the excitation current was $25 \mathrm{~A}$, and the motor was operated at $250 \mathrm{rpm}$. We can see that the sine wave still keeps smooth even though the iron core is employed. It means the torque ripple will not be too important.

The analysis of the flux density and output torque at rated condition are presented as follows. $400 \mathrm{~kW}$ output was obtained at $250 \mathrm{rpm}$. Fig. 4(a) and (b) show the analytical result of the flux density on the HTS wires, where the Fig. 4(a) shows the flux at horizontal direction with the field winding and Fig. 4(b) shows the result when the flux is perpendicular to the field winding. The maximum flux density is $0.24 \mathrm{~T}$ at horizontal direction and is $0.36 \mathrm{~T}$ at vertical direction.

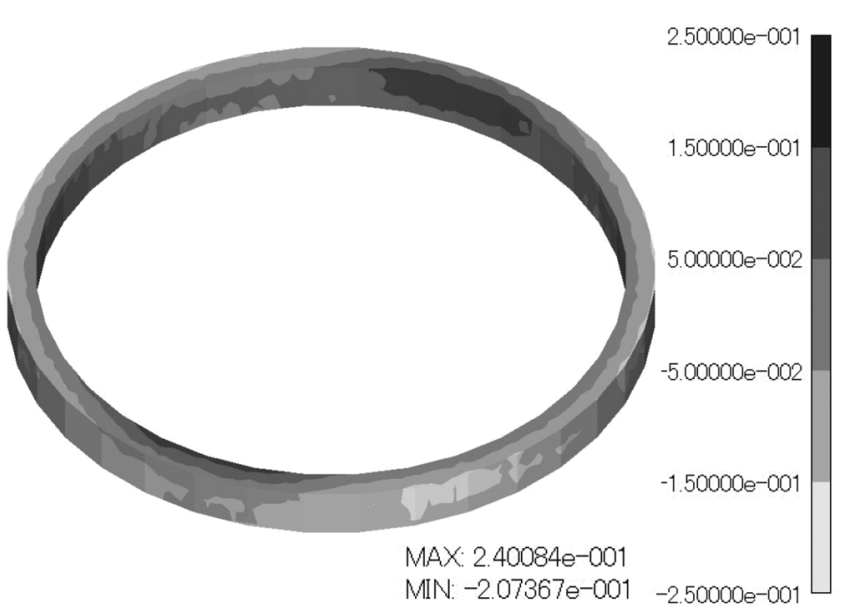

(a)

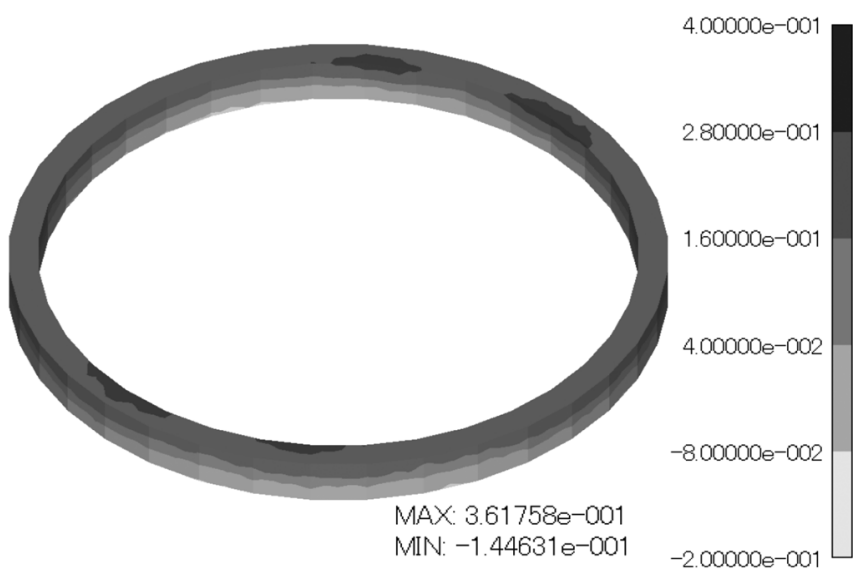

(b)

Fig. 4. Contour figure of the flux density on field HTS winding. (a) Horizontal direction. (b) Vertical direction.

Figs. 5(a) and (b) show the analytical results of the density of the flux which penetrates the armature winding, where the Fig. 5(a) shows the flux at the horizontal direction of armature winding and Fig. 5(b) shows the flux is perpendicular to the armature winding. When the armature current reaches its peak value, the flux density will also reach its peak value which is $0.09 \mathrm{~T}$ at the horizontal direction and is $0.35 \mathrm{~T}$ at the vertical direction.

According to Fig. 4 and Fig. 5, the critical current is not exceeded, so the HTS wires can be operated continually at those values without problems. As we mentioned before, the majority of the load torque acts on the iron core, so the torque applied on the windings can be very low. It is about $120 \mathrm{Nm}$ per winding. It means even without stainless reinforced steels, the HTS wire can still work well.

The losses of this machine are discussed as follow. First, Let us see the AC loss. The motor operated at low flux density on the armature winding and the low frequency of the armature current $(16.7 \mathrm{~Hz})$. It can be concluded that the HTS wires' AC loss is low. The next is the iron losses. As we mentioned before, the inductors, back yoke and armature core are all placed at the outside of the cryostat. There is not much iron loss of the inductors because the inductors are mainly used at DC condition. This motor's axial flux type also leads to low iron loss on the back 


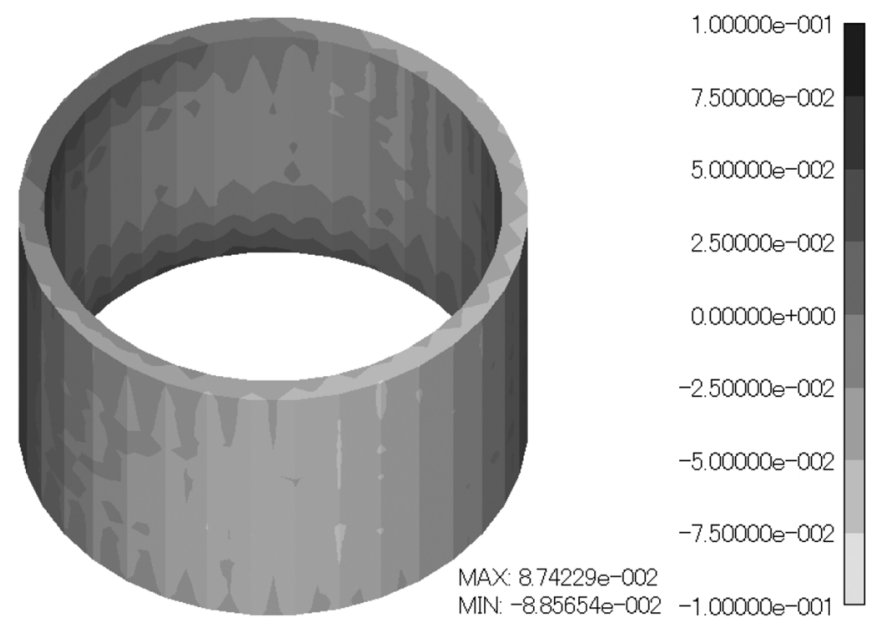

(a)

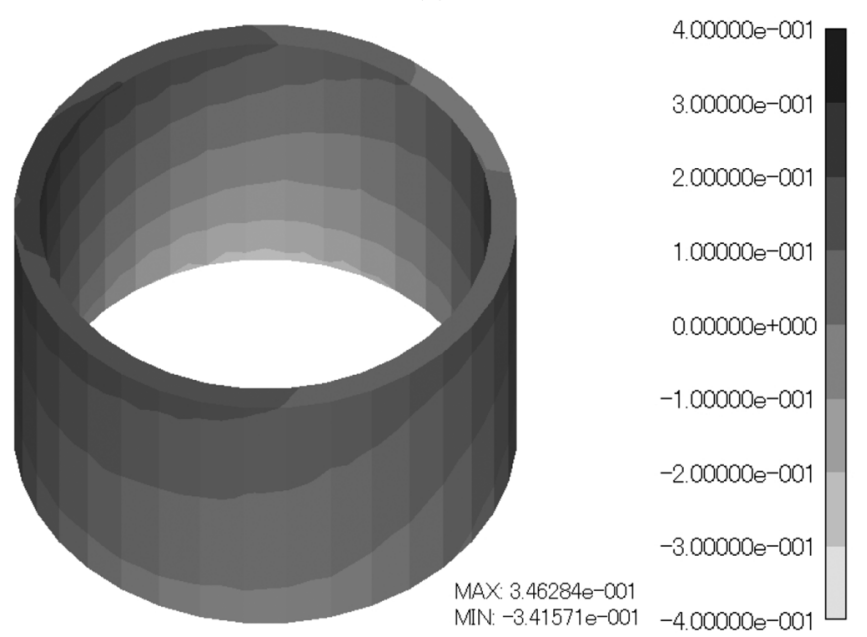

(b)

Fig. 5. Contour figure of the flux density on armature HTS winding. (a) Horizontal direction. (b) Vertical direction.

yoke. According to the specification of the material of the armature core, the iron loss is $6.3 \mathrm{~W} / \mathrm{kg}$ at room temperature when the maximum flux density is $1.5 \mathrm{~T}$ and the frequency is $50 \mathrm{~Hz}$. When the iron core is placed at room temperature, we supposed that the maximum average flux density is $1.5 \mathrm{~T}$, according to the following expression, the iron loss is $860 \mathrm{~W}$.

$$
W_{f} \approx W_{f_{1}}\left(f / f_{1}\right)^{1.6}
$$

Where $W_{f}$ is the iron loss when the frequency is $f ; W_{f 1}$ is the iron loss when the frequency is $f_{1}$.
This is a quite low value compared to $400 \mathrm{~kW}$ output. Totally, the whole iron losses of this motor are pretty low. To sum up, there is low AC loss, low iron loss. This means, a high efficiency motor could be achieved.

\section{CONCLUSION}

From the above discussion, even though at a relatively high temperature (liquid nitrogen temperature) it is still possible to make a high performance variable field type electric motor by applying the HTS wires both to the field and the armature, and applying iron core to the armature. Moreover, the cooling system can be simplified by using the proposed inductors configuration to the rotor. The motor that we designed is under production now. Its characteristics will be tested after it is finished.

It is generally recognized that miniaturization of HTS motors cannot be well performed on a small machine. It is known that a high capacity motor needs a large size. Another meaning that we can achieve motor miniaturization is when we can make high output motor without significantly increasing the size as the conventional one. Because the thicknesses of the vacuum layer and the liquid nitrogen layer of the cryostat are constant. The increase on the cryostat size takes up a small portion of the increase on the motor. The larger the motor is, the more apparent the advantage can be seen.

In the future, we are planning to make higher output motor for practical use.

\section{REFERENCES}

[1] O. Tsukamoto, N. Amemiya, and K. Yamagishi, "Development and electrical test of a $30 \mathrm{kVA}$ class fully superconducting generator," IEEE Trans. Magnetics, vol. 30, no. 4, pp. 2308-2311, July 1994.

[2] P. Tixador and H. Daffix, "Conceptual design of an electrical machine with both low and high Tc superconductors," IEEE Trans. Applied Superconductivity, vol. 7, no. 4, pp. 3858-3865, December 1997.

[3] P. W. Eckels and G. Snitcher, "5 MW high temperature superconductor ship propulsion motor design and test result," in Naval Symposium on Electric Machines, Philadelphia, PA, January 2004.

[4] M. K. Al-Mosawi, C. Beduz, and Y. Yang, "Construction of a 100 kVA high temperature superconducting synchronous generator," IEEE Trans. Applied Superconductivity, vol. 15, no. 2, pp. 2182-2185, June 2005.

[5] G. Klaus, W. Nick, H.-W. Neumüller, G. Nerowski, and W. McCown, "Advances in the development of synchronous machines with hightemperature superconducting field winding at Siemens AG," presented at the IEEE PES, 2006.

[6] H. Sugimoto, T. Nishikawa, T. Tsuda, Y. Hondou, Y. Akita, T. Takeda, T. Okazaki, S. Ohashi, and Y. Yoshida, "Trial manufacture of liquid nitrogen cooling high temperature superconductivity motor,' in Journal of Physics: Conference Series, 2006, vol. 43, pp. 780-783.

[7] T. Okazaki, H. Sugimoto, and T. Takeda, "Liquid nitrogen cooled HTS motor for ship propulsion," presented at the IEEE PES, 2006. 